\title{
Chemoprevention of breast cancer by cyclooxygenase and lipoxygenase inhibitors
}

\author{
RANDALL E. HARRIS, JOANNE BEEBE and JUDITH A. SCHWARTZBAUM \\ The Ohio State University Colleges of Medicine and Public Health, \\ The Ohio State University Comprehensive Cancer Center, Columbus, OH 43210, USA
}

Received December 4, 2019; Accepted January 24, 2020

DOI: $10.3892 /$ wasj.2020.34

\begin{abstract}
Numerous epidemiological and laboratory investigations have demonstrated that non-steroidal anti-inflammatory drugs (NSAIDs) exert chemopreventive effects against breast cancer due to their activity against cyclooxygenase $(\mathrm{COX})$, the enzyme that responds to tissue damage by producing inflammatory prostaglandins. Recent laboratory and animal investigations have suggested that a second group of anti-inflammatory compounds, those that inhibit lipoxygenase (LOX)-catalyzed products of the leukotriene cascade, may also have potential for breast cancer chemoprevention and therapy. Therefore, in this study, a case-control investigation was conducted to examine the independent and combined effects of COX and LOX inhibitors in the prevention of breast cancer. A total of 611 incident breast cancer patients were identified and they were compared to 615 cancer-free controls, group-matched to the cases on age, race and county of residence. Data on the past and current use of medications and breast cancer risk factors were ascertained using medical records and a risk factor questionnaire. The results revealed risk reductions for $\mathrm{COX}$ (OR, 0.38; 95\% CI, 0.27-0.54) and LOX inhibitors (OR, 0.52; 95\% CI, 01.32-0.82). Notably, their combined use produced the greatest risk reduction $(\mathrm{OR}, 0.26 ; 95 \% \mathrm{CI}=0.11-0.65)$. On the whole, the findings of this study suggest that combinations of compounds with independent effects against COX and LOX have a stronger potential to prevent breast cancer than do the individual compounds.
\end{abstract}

Correspondence to: Dr Randall E. Harris, The Ohio State University Colleges of Medicine and Public Health, The Ohio State University Comprehensive Cancer Center, 1841 Neil Avenue, Columbus, OH 43210, USA

E-mail: harris.44@osu.edu

Abbreviations: COX, cyclooxygenase; LOX, lipoxygenase

Key words: breast cancer, chemoprevention, cyclooxygenase, lipoxygenase

\section{Introduction}

Chronic inflammation of the mammary epithelium may result from tissue damage, leading to the sustained overexpression of cyclooxygenase (COX) and biosynthesis of inflammatory prostaglandins from arachidonic acid. This inflammatory environment may stimulate key components of mammary carcinogenesis (mitogenesis, mutagenesis, angiogenesis, reduced apoptosis, immunosuppression and metastasis), potentially leading to the development of breast cancer. Reciprocally, agents that inhibit COX reduce the risk of breast cancer $(1,2)$. Lipoxygenase (LOX) enzymes also create an inflammatory environment by catalyzing the conversion of arachidonic acid to inflammatory eicosanoids, principally hydroperoxy-eicosatetraenoic acid (HPETE) and leukotrienes. The overexpression of LOX promotes the development of certain autoimmune conditions (rheumatoid arthritis) and allergic reactions (asthma). Accumulating evidence from laboratory and animal studies suggests that the overexpression of LOX promotes carcinogenesis, and reciprocally, agents that inhibit the LOX cascade interrupt cancer development (3-6).

Notably, a recent investigation of gene expression data in tissue samples from 1,090 cases of invasive breast cancer from The Cancer Genome Atlas (TCGA) revealed that genes encoding COX-1 and COX-2, and two LOX proteins, arachidonate lipoxygenase-5 (ALOX-5) and ALOX-5-activating protein (ALOX-5AP), were expressed in all subtypes of breast cancer. In addition, the expression levels of these inflammatory genes were highly correlated with the expression levels of 18 tumor promoting genes with documented involvement in mammary carcinogenesis. Inflammatory genes were also highly correlated with CYP-19 P-450 arom (aromatase) in all breast cancer subtypes, suggesting the importance of sustained paracrine estrogen biosynthesis in breast cancer development (7).

To the best of our knowledge, only one known previous human study has reported the effects of LOX inhibitors on breast cancer risk among women and it examined only subjects with asthma (8). This nested cohort study conducted in Taiwan found that among women with reported asthma, the use of certain LOX inhibiting drugs [cysteinyl leukotriene receptor antagonists (LTRAs)], significantly reduced their risk of breast cancer as well as their overall cancer risk. The investigators reported that, at a given time, for every 31 cancer cases identified in the LTRA treatment group, there were 69 in the 
untreated group. Their findings for breast cancer were stronger. Stratifying on the type of cancer, they found that for every 9 breast cancer cases among the LTRA-treated group, there were 91 among the untreated group [hazard ratio (HR), 0.09; 95\% confidence interval (CI), 0.03-0.26] (8).

An emerging consensus in the field of chemoprevention is that the complexities of the carcinogenic process will require a combination of agents targeting multiple pathways involved in the inflammogenesis of breast cancer to achieve optimal efficacy. Nevertheless, there are no known human studies on the effects of LOX inhibitors or the combined use of COX and LOX inhibitors on breast cancer in the general female population. Therefore, herein, an epidemiological case-control study was conducted to investigate the association of breast cancer risk with exposure to compounds that modulate either the COX or LOX cascades, or both.

\section{Patients and methods}

Patients. A total of 611 cases of invasive breast cancer with histological verification based on the review of the pathology records, and 615 group-matched controls with no personal history of cancer and no current breast disease based on screening mammography were examined. Cases were interviewed at the time of their diagnosis during 2003 through September, 2004 at The Arthur G. James Cancer Hospital and Richard J. Solove Research Institute, Columbus, Ohio. The controls were patients at the mammography service of the cancer hospital during the same time period and frequency matched to the cases by 5-year age interval, race and place (county) of residence. Screening mammography findings were normal for all controls. The study was approved by The Ohio State University Medical Center Institutional Review Board (IRB) and conducted in full compliance with ethical standards of the US National Institutes of Health for human medical research. Written informed consent was obtained from each study participant to provide information for analysis and publication of results.

Information on COX- and LOX-modulating agents and other factors was obtained utilizing medical records and a standardized risk factor questionnaire. The questionnaires were administered in person by trained medical personnel prior to definitive surgery or treatment for the cases and at the time of screening mammography for controls. The data variables collected consisted of demographic characteristics, height, weight, menstrual and pregnancy history, family history of breast and ovarian cancer, comprehensive information on cigarette smoking, alcohol intake, pre-existing medical conditions (arthritis, chronic headache, cardiovascular conditions including hypertension, angina, ischemic attacks, stroke and myocardial infarction, lung disease, and diabetes mellitus), and medication history including over the counter and prescription agents.

The usage patterns of COX and LOX modulating agents (frequency, dose and duration) and the type were recorded for each participant. The COX inhibitors included compounds selective for COX-2 (celecoxib, rofecoxib and meloxicam) and non-selective (COX-1 or COX-2 or both) non-steroidal anti-inflammatory drugs (NSAIDs), such as aspirin, ibuprofen, naproxen and indomethacin. The LOX-modulating agents prescribed for the treatment of asthma included zileuton, an
Table I. Characteristics of breast cancer cases and controls.

\begin{tabular}{|c|c|c|}
\hline Characteristic $^{\mathrm{a}}$ & $\begin{array}{c}\text { Cases } \\
(n=611)(\%)\end{array}$ & $\begin{array}{c}\text { Controls } \\
(\mathrm{n}=615)(\%)\end{array}$ \\
\hline \multicolumn{3}{|l|}{ Age (years) } \\
\hline$<50$ & 19 & 20 \\
\hline $50-65$ & 55 & 52 \\
\hline$>65$ & 26 & 28 \\
\hline Mean (SEM) & $55.8(0.8)$ & $55.2(0.4)$ \\
\hline \multicolumn{3}{|l|}{ Race } \\
\hline Caucasian & 91 & 89 \\
\hline All other & 9 & 11 \\
\hline \multicolumn{3}{|l|}{ Education } \\
\hline$<12$ years & 12 & 12 \\
\hline 12 years & 53 & 55 \\
\hline$>12$ years & 31 & 33 \\
\hline \multicolumn{3}{|l|}{ Parity } \\
\hline Nulliparous & 6 & 4 \\
\hline First pregnancy $<30$ years & 83 & 89 \\
\hline First pregnancy $>30$ years & 11 & $7(\mathrm{P}<0.05)$ \\
\hline \multicolumn{3}{|l|}{ Family history } \\
\hline Positive & 32 & 17 \\
\hline Negative & 68 & $83(\mathrm{P}<0.01)$ \\
\hline \multicolumn{3}{|l|}{ Body mass } \\
\hline BMI $<22$ & 23 & 21 \\
\hline BMI 22-28 & 35 & 39 \\
\hline $\mathrm{BMI}>28$ & 42 & 40 \\
\hline Mean (SEM) & $27.5(0.9)$ & $27.1(0.7)$ \\
\hline \multicolumn{3}{|l|}{ Menopausal status } \\
\hline Premenopausal & 41 & 47 \\
\hline Postmenopausal & 52 & 53 \\
\hline Postmenopausal ERT & 38 & $31(\mathrm{P}<0.05)$ \\
\hline \multicolumn{3}{|l|}{ Smoking } \\
\hline Never smoker & 35 & 32 \\
\hline Ex-smoker & 38 & 40 \\
\hline Current smoker & 27 & 28 \\
\hline \multicolumn{3}{|l|}{ Alcohol intake } \\
\hline None & 47 & 45 \\
\hline 1-2 drinks per week & 36 & 35 \\
\hline$>2$ drinks per week & 17 & 20 \\
\hline
\end{tabular}

${ }^{\mathrm{a}}$ Family history: Either breast or ovarian cancer among first or second degree female relatives. ERT, estrogen replacement therapy for $\geq 2$ years; body mass index represents weight $(\mathrm{kg}) / \mathrm{height}^{2}(\mathrm{~m})$. Case-control differences in means and frequencies were tested for statistical significance by t-tests and Chi-square tests, respectively.

inhibitor of 5-lipoxygenase, bestatin, an inhibitor of leukotriene $\mathrm{B} 4$, the leukotriene receptor antagonists, pranlukast, montelukast and zafirlukast, as well as theophylline and cromolyn sodium. Since the frequency of using LOX-modulating medications was low (approximately 10\%), exposure to these compounds was investigated by pooling the use of any of them. 
Table II. Odds ratios with $95 \%$ confidence intervals for breast cancer and COX inhibitors, LOX inhibitors, and the combined use of COX and LOX (COX/LOX) inhibitors.

\begin{tabular}{lccr}
\hline Compound & Cases & Controls & Adjusted OR $(95 \% \text { CI })^{\mathrm{b}}$ \\
\hline Reference $^{\mathrm{a}}$ & 480 & 353 & 1.00 \\
COX Inhibitors & 95 & 200 & $0.38(0.27-0.54)(\mathrm{P}<0.001)$ \\
LOX Inhibitors & 27 & 39 & $0.52(0.32-0.82)(\mathrm{P}<0.01)$ \\
COX/LOX Inhibitors & 9 & 23 & $0.26(0.11-0.64)(\mathrm{P}<0.01)$ \\
Totals & 611 & 615 & \\
\hline
\end{tabular}

${ }^{\mathrm{a}}$ No reported use of any agents that inhibit COX or LOX. ${ }^{\mathrm{b}}$ Multivariate odds ratios are adjusted for continuous variables (age and body mass) and categorical variables (parity, menopausal status, family history, smoking and alcohol intake). Numbers shown for COX and LOX inhibitors do not include numbers for joint users. COX, cyclooxygenase; LOX, lipoxygenase.

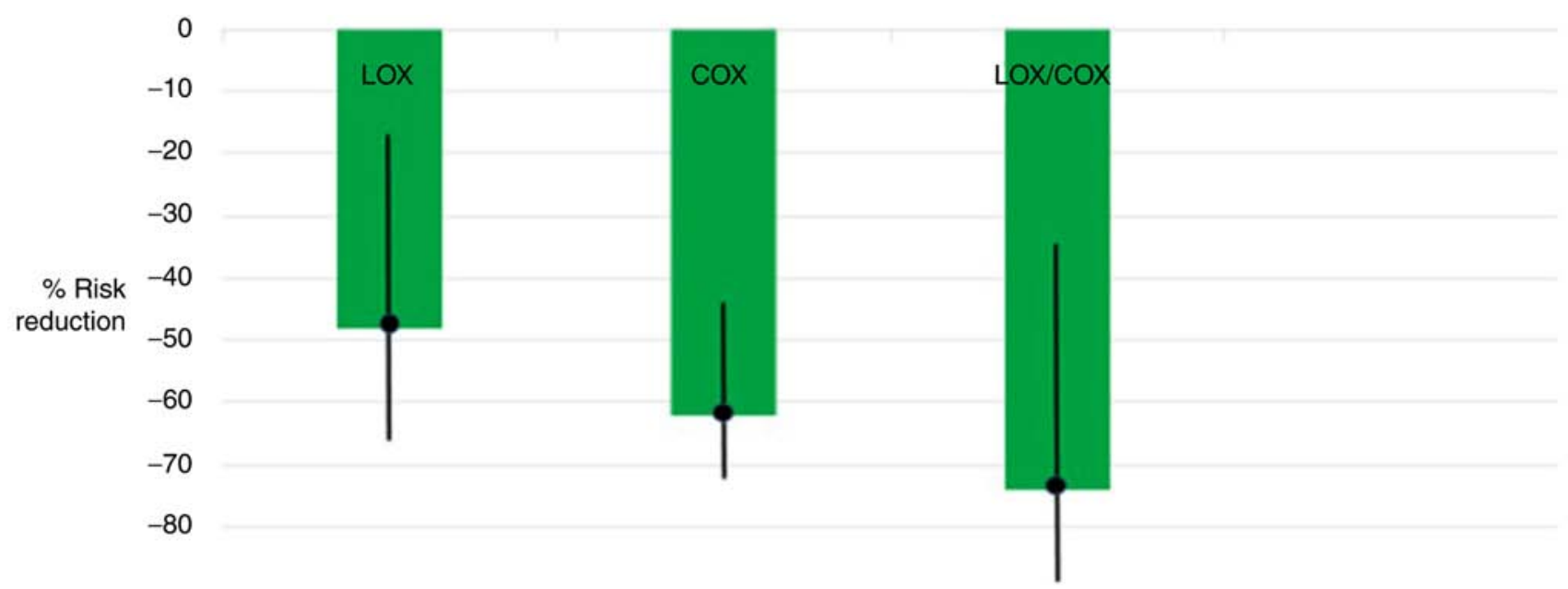

Figure 1. Estimated risk reductions in breast cancer with the intake of LOX, COX and LOX/COX inhibitors. Error bars denote $95 \%$ confidence intervals. COX, cyclooxygenase; LOX, lipoxygenase.

Statistical analysis. Case-control differences in means and frequencies were examined for statistical significance by t-tests and Chi-square tests, respectively. Logistic regression was used to estimate odds ratios (ORs) to quantify the association between the pre-diagnostic use of COX and LOX inhibitors, separately and together, with breast cancer risk. The ORs were adjusted for age and classic breast cancer risk factors (parity, family history, body mass, menopausal status, chronic smoking and regular alcohol intake). Estimates of the independent effects of COX or LOX inhibitors also were adjusted for each other $(9,10)$.

\section{Results}

The pertinent characteristics of the cases and controls are presented in Table I. The cases exhibited higher frequencies of nulliparity, a family history of breast or ovarian cancer and estrogen replacement therapy in post-menopausal subjects. As expected, (due to group matching), the cases and controls had similar distributions of age, race and education.

The comparative frequencies of the COX and LOX modulating agents under study with adjusted ORs and their 95 CIs are shown in Table II. In the table, the numbers of cases and controls using both COX and LOX inhibitors are shown separately from those using only individual compounds.

Risk reductions were found for COX (OR, 0.38; 95\% CI, 0.27-0.54; $\mathrm{P}<0.001)$ and LOX inhibitors (OR, 0.52; 95\% CI, $0.32-0.82 ; \mathrm{P}<0.01)$. Notably, the combined use of COX and LOX inhibitors produced the greatest risk reduction (OR, $0.26 ; 95 \%$ CI, 0.11-0.64; $\mathrm{P}<0.01)$. These results are illustrated in Fig. 1. In Fig. 1, the ORs with $95 \%$ CIs were converted to percentage risk reductions by subtracting estimates from 1.0 and multiplying by 100 . Estimates were similar with and without adjustment for potential confounders and among subgroups by menopausal status, the use of estrogen replacement therapy and family history.

\section{Discussion}

In this case control study, it was found that the separate use of either COX or LOX inhibitors reduces breast cancer risk. In addition, in this first known study to evaluate the joint effects of these anti-inflammatory agents, their combined use produced a greater effect than their individual use.

The findings of this study for LOX inhibitors are consistent with those of previous molecular studies, suggesting that the overexpression of leukotrienes and leukotriene receptors 
are associated with prominent features of mammary carcinogenesis, including cell proliferation, angiogenesis, reduced apoptosis and metastasis $(11,12)$. For example, leukotriene B4 (LBT4) is a major inflammatory factor in the ALOX-5 cascade that modulates inflammatory and carcinogenic effects through two cell membrane receptors, BLT1 and BLT2. Elevated levels of LBT4 and its receptors have been observed in cancerous tissues of breast cancer, as well as in numerous other human malignancies including colon cancer, prostate cancer, ovarian cancer, renal cancer, pancreatic cancer, esophageal cancer, lung cancer and neuroblastoma (13-25).

The results of this study are also supported by those of previous preclinical studies demonstrating that leukotriene inhibitors, a therapeutic category that includes the asthma medications montelukast (Singulair $\left.{ }^{\circledR}\right)$, zafirlukast $\left(\right.$ Accolate $^{\circledR}$ ), zileuton $\left(\mathrm{Zyflo}^{\circledR}\right)$ and ubenimex (bestatin), inhibit tumors of the lung, esophagus and colon (26-29). Finally, to the best of our knowledge, the only known human study to examine the effects of leukotriene inhibiting asthma medication found an overall reduced risk of cancer, in general, as well as of breast cancer, in particular; however, this study was limited to asthmatic patients (8).

The breast cancer risk-reducing properties of COX inhibitors observed herein are consistent with a large body of previous literature demonstrating the cancer risk-reducing properties of these agents (1-4). The results for COX inhibitors in the present study have been previously reported in more detail (30). In brief, effects were observed for selective inhibitors of COX-2, such as celecoxib (OR, 0.15; 95\% CI, 0.08-0.28) and non-selective over the counter agents, such as aspirin and ibuprofen (OR, 0.43; 95\% CI, 0.25-0.55).

This study has two limitations. First, this study did not include the conditions for which the COX and LOX medications were used. This information is necessary to determine whether the findings are attributable to the medication per se or the causes for which the medication was administered. For example, it has been shown that allergies and hay fever, which are related to asthma risk, are associated with a reduced risk of breast cancer (31). Possibly, of greater concern for interpreting the findings of this study, is that the same study found an inverse association between asthma and breast cancer risk among premenopausal women. The second limitation is that the sample size in this study was too small to evaluate the effects of individual medications. Further studies using larger sample sizes are required to investigate independent and joint effects of these inflammation-inhibiting compounds.

In conclusion, this study observed significant reductions in the risk of human breast cancer with the intake of agents that inhibit the COX and LOX inflammatory cascades. The greatest risk reduction $(74 \%)$ was observed with combined use of agents that inhibit both COX and LOX. The findings of this study suggest that combining agents that inhibit both the COX and LOX inflammatory cascades has strong potential for breast cancer chemoprevention. Nevertheless, the risk-benefit ratio of combining COX and LOX inhibitors for chemoprevention has yet to be determined and the results must therefore be judiciously considered. The novel findings of this study thus require replication.

\section{Acknowledgements}

The authors would like to thank Elvira M. Garofalo, Program Manager of the James Cancer Mammography Unit, and Julie M. Coursey, Assistant Director of the James Cancer Medical Records Registry, for their assistance in the conduct of this investigation.

\section{Funding}

This study was supported in part by a grant from Pfizer, New York, NY, and grant P30 CA16058 from the National Cancer Institute, Bethesda, MD, USA.

\section{Availability of data and materials}

All data generated or analyzed during this study are included in this published article or are available from the corresponding author on reasonable request.

\section{Authors' contributions}

REH designed and directed the study. JB assisted in study design, coordinated data collection and quality control, and assisted in the interpretation of results. JAS assisted in study design and the analysis and interpretation of results.

\section{Ethics approval and consent to participate}

The study was approved by The Ohio State University Medical Center Institutional Review Board (IRB) and conducted in full compliance with ethical standards of the US National Institutes of Health for human medical research. Written informed consent was obtained from each study participant to provide information for analysis and publication of results.

\section{Patient consent for publication}

Not applicable.

\section{Competing interests}

The authors declare that they have no competing interests.

\section{References}

1. Harris RE: Cyclooxygenase-2 (cox-2) blockade in the chemoprevention of cancers of the colon, breast, prostate, and lung. Inflammopharmacology 17: 1-13, 2009.

2. Harris RE, Casto BC and Harris ZM: Cyclooxygenase-2 and the inflammogenesis of breast cancer. World J Clin Oncol 5: 677-692, 2014.

3. Steele VE, Holmes CA, Hawk ET, Kopelovich L, Lubet RA, Crowell JA, Sigman CC and Kelloff GJ: Lipoxgenase inhibitors as potential cancer chemopreventives. Cancer Epidemiol Biomarkers Prev 8: 467-483, 1999.

4. Wang D and Dubois RN: Eicosanoids and cancer. Nat Rev Cancer 10: 181-193, 2010.

5. Schneider C and Pozzi A: Cyclooxygenases and lipoxygenases in cancer. Cancer Metastasis Rev 30: 277-294, 2011.

6. Wisastra R and Dekker FJ: Inflammation, cancer and oxidative lipoxygenase activity are intimately linked. Cancers (Basel) 6: $1500-1521,2014$ 
7. Kennedy BM and Harris RE: Cyclooxygenase and lipoxygenase gene expression in the inflammogenesis of breast cancer Inflammopharmacology 26: 909-923, 2018.

8. Tsai MJ, Wu PH, Sheu CC, Hsu YL, Chang WA, Hung JY, Yang CJ, Yang YH, Kuo PL and Huang MS: Cysteinyl leukotriene receptor antagonists decrease cancer risk in asthma patients. Sci Rep 7: 23979, 2016.

9. Schlesselman JJ: Case control studies. Oxford University Press, New York, NY, 1982

10. Harrell F: Logistic regression procedure. Statistical Analysis System (SAS), 2005

11. Jiang WG, Douglas-Jones AG and Mansel RE: Aberrant expression of 5-lipoxygenase-activating protein (5-LOXAP) has prognostic and survival significance in patients with breast cancer. Prostaglandins Leukot Essent Fatty Acids 74: 125-134, 2006.

12. Wang J, John EM and Ingles SA: 5-lipoxygenase and 5-lipoxygenase-activating protein gene polymorphisms, dietary linoleic acid, and risk for breast cancer. Cancer Epidemiol Biomarkers Prev 17: 2748-2754, 2008

13. Choi JA, Lee JW, Kim H, Kim EY, Seo JM, Ko J and Kim JH Pro-survival of estrogen receptor-negative breast cancer cells is regulated by a BLT2-reactive oxygen species-linked signaling pathway. Carcinogenesis 31: 543-551, 2010.

14. Kim H, Choi JA, Park GS and Kim JH: BLT2 up-regulates interleukin-8 production and promotes the invasiveness of breas cancer cells. PLoS One 7: e49186, 2012.

15. Haeggström JZ and Funk CD: Lipoxygenase and leukotriene pathways: Biochemistry, biology, and roles in disease. Chem Rev 111: 5866-5898, 2011.

16. Jiang WG, Douglas-Jones A and Mansel RE: Levels of expression of lipoxygenases and cyclooxygenase-2 in human breast cancer. Prostaglandins Leukot Essent Fatty Acids 69: 275-281, 2003.

17. Soumaoro LT, Iida S, Uetake H, Ishiguro M, Takagi Y, Higuchi T, Yasuno M, Enomoto M and Sugihara K: Expression of 5-lipoxygenase in human colorectal cancer. World J Gastroenterol 12 6355-6360, 2006.

18. Kleinstein SE, Heath L, Makar KW, Poole EM, Seufert BL, Slattery ML, Xiao L, Duggan DJ, Hsu L, Curtin K, et al: Genetic variation in the lipoxygenase pathway and risk of colorectal neoplasia. Genes Chromosomes Cancer 52: 437-449, 2013.

19. Ghosh J and Myers CE: Arachidonic acid stimulates prostate cancer cell growth: Critical role of 5-lipoxygenase. Biochem Biophys Res Commun 235: 418-423, 1997.

20. Rocconi RP, Kirby TO, Seitz RS, Beck R, Straughn JM Jr, Alvarez RD and Huh WK: Lipoxygenase pathway receptor expression in ovarian cancer. Reprod Sci 15: 321-326, 2008.
21. Faronato M, Muzzonigro G, Milanese G, Menna C, Bonfigli AR, Catalano A and Procopio A: Increased expression of 5-lipoxygenase is common in clear cell renal cell carcinoma. Histol Histopathol 22: 1109-1118, 2007.

22. Tong WG, Ding XZ, Talamonti MS, Bell RH and Adrian TE: LTB4 stimulates growth of human pancreatic cancer cells via MAPK and PI-3 kinase pathways. Biochem Biophys Res Commun 335: 949-956, 2004

23. Hennig R, Grippo P, Ding XZ, Rao SM, Buchler MW, Friess H, Talamonti MS, Bell RH and Adrian TE: 5-Lipoxygenase, a marker for early pancreatic intraepithelial neoplastic lesions. Cancer Res 65: 6011-6016, 2005.

24. Chen X, Wang S, Wu N, Sood S, Wang P, Jin Z, Beer DG, Giordano TJ, Lin Y, Shih WC, et al: Overexpression of 5-lipoxygenase in rat and human esophageal adenocarcinoma and inhibitory effects of zileuton and celecoxib on carcinogenesis. Clin Cancer Res 10: 6703-6709, 2005.

25. Sveinbjörnsson B, Rasmuson A, Baryawno N, Wan M, Pettersen I, Ponthan F, Orrego A, Haeggström JZ, Johnsen JI and Kogner P: Expression of enzymes and receptors of the leukotriene pathway in human neuroblastoma promotes tumor survival and provides a target for therapy. FASEB J 22: 3525-3536, 2008.

26. Rioux $\mathrm{N}$ and Castonguay A: Inhibitors of lipoxygenase: A new class of cancer chemopreventive agents. Carcinogenesis 19: 1393-1400, 1998.

27. Mashima R and Okuyama T: The role of lipoxygenases in pathophysiology: New insights and future perspectives. Redox Biol 6: 297-310, 2015.

28. Moore GY and Pidgeon GP: Cross-talk between cancer cells and the tumour microenvironment: The role of the 5-lipoxygenase pathway. Int J Molecular Sciences 18: 236, 2017.

29. Zhao S, Yao K, Li D, Liu K, Jin G, Yan M, Wu Q, Chen H, Shin SH, Bai R, et al: Inhibition of LTA4H by bestatin in human and mouse colorectal cancer EBioMedicine 44: 361-374, 2019.

30. Harris RE, Beebe-Donk J and Alshafie GA: Reduction in the risk of human breast cancer by selective cyclooxygenase-2 (COX-2) inhibitors. BMC Cancer 6: 27, 2006.

31. Lowcock EC, Cotterchio M and Ahmad N: Association between allergies, asthma, and breast cancer risk among women in Ontario, Canada. Cancer Causes Control 24: 1053-1056, 2013.

This work is licensed under a Creative Commons Attribution-NonCommercial-NoDerivatives 4.0 International (CC BY-NC-ND 4.0) License. 